DOI: $10.20472 /$ IAC.2018.040.028

\author{
JOLANTA JONAK \\ Northeastern Illinois University, United States \\ SYLVIA TOLCZYK \\ Main South High School, United States
}

\title{
REACHING EACH STUDENT'S POTENTIAL THOUGH DIFFERENTIAL INSTRUCTION APPROACHES TO ENHANCE THE 21 CENTURY LEARNING AND CAREER READINESS
}

\begin{abstract}
:
In the ever-increasing global society, educational systems become increasingly diverse. The diversity comes in various forms, cultural and linguistic differences, learning preferences and styles, ability and disability. The trend in current educational systems is to tap into each student's potential. Unfortunately conventional methods do not always work when students' needs are more unique. Many teachers do not have the educational background or training to know how to teach students whose learning needs may vary from the norm. Also, teachers frequently do not have consistent access to interventionists that are well trained in knowing how to provide an environment that meets the needs of all students, no matter what their academic needs may be.

One way to ensure successful education for all students is by providing Differentiated Instruction (DI). Differentiated Instruction is a model that is founded on the basic principles of Universal Design for Learning. This form of support ensures that regardless of the students' learning preferences and cognitive learning profiles, they have an opportunity to learn through approaches that are suitable to their needs.

When implemented by classroom teachers, it not only improves the educational outcomes of the students with special needs but benefits all students in that it accommodates learning styles as well as the scope of unique learning needs that are evident in the typical classroom setting. Differentiated Instruction also is recognized as an evidence-based best practice in education and is highly effective when it is actively implemented in Tier One, Tier Two, and Tier Three of the Response to Intervention (RTI) model. While many are familiar with the term, Differentiated Instruction, what is missing is that many teachers do not understand what strategies are implemented in the classroom that create the unique learning environment for each student within the same setting. With knowledge of a variety of instructional strategies, teachers can facilitate optimal learning for all students, with and without a disability. Facilitation of DI also avoids inaccurate perceptions about the students' learning abilities, unnecessary referrals for special education evaluations, and inaccurate decisions about the presence of a disability.

In this presentation, we will illustrate the fundamentals of Differentiated Instruction and provide a variety of strategies that are considered best practices in enhancing the learning of all students in the educational setting.
\end{abstract}

\section{Keywords:}

Differentiated Instruction, learning strategies, learning differences, and learning disabilities, learning potential. 
JEL Classification: 129 